Науковий вісник Дьвівського націонадьного університету ветеринарної медицини та біотехнологій імені С.3. Гжицького

\author{
Scientific Messenger of Lviv National University \\ of Veterinary Medicine and Biotechnologies
}

\title{
A comparative study of the reproductive traits and clustering analysis among different pig breeds
}

\author{
S.S. Kramarenko, S.I. Lugovoy, A.V. Lykhach, A.S. Kramarenko, V.Ya. Lykhach \\ Mykolayiv National Agrarian University, Mykolayiv, Ukraine
}

Article info

Received 16.01.2018

Received in revised form 19.02.2018

Accepted 23.02.2018

Mykolayiv National Agrarian University, 9, Georgiya Gongadze Str., Mykolayiv, 54020, Ukraine Tel.: +38-050-991-53-14 E-mail:kssnail0108@gmail.com
Kramarenko, S.S., Lugovoy, S.I., Lykhach, A.V., Kramarenko, A.S., Lykhach, V.Ya. (2018). A comparative study of the reproductive traits and clustering analysis among different pig breeds. Scientific Messenger of Lviv National University of Veterinary Medicine and Biotechnologies. 20(84), 21-26. doi: 10.15421/nvlvet8404

The data were from 149 pigs from seven pig genetic groups raised in «Tavriys'ki Svyni» Ltd (Kherson region, Ukraine). The following genetic groups were included in our analyses: $L W \times L W(n=19)$, $L W \times L N(n=43), L W \times P T(n=13), L N \times L N(n=15), U M \times L N(n=23), U M \times P T(n=17)$ and $U M \times U M(n=16)$. The objective this work was evaluation of animal reproductive traits using multivariate analysis. Variables measured and derived included total no. piglets born (TNB), no. piglets born alive (NBA), freq. of stillborn piglets (FSB), total litter birth weight (TLBW), average piglet birth weight $(A P B W)$, pre-weaning mortality in piglets $(P W M)$, no. weaned piglets $(N W)$, total weaning weight of litter $(T W W L)$ and average piglet weaning weight $(A P W W)$. After standardization, multivariate analyses (Cluster analysis and Principal Component Analysis) were carried out using STATISTICA (StatSoft Ltd.) to place pig interbreeding combinations in groups in accordance with their degree of similarity and verify discriminatory capacity of the original traits in the formation of these groups. The tree diagram showed clear distances between the pig genetic groups studied. In the tree diagram obtained from the analysis of the distances between interbreeding combinations, two distinct groups (clusters) were seen, one with $U M \times L N$ and $U M \times U M$ animals, and the other with the rest of the pig genetic groups in the study. The eigenvalues for the first two Principal Components (PC1 and PC2) together accounted for near $65 \%$ of the variance of the pig's reproductive traits. The first principal component (PC1) explained $34.9 \%$ total variation. It was represented by significant positive loadings for TNB, NBA and TLBW. The second principal component (PC2) accounted for an additional $29.7 \%$ of the generalized variance and was represented by significant loadings for NW, TWWL and APWW. Thus, PC1 defined no. piglets and total litter birth weight, while PC2 represented no. weaned piglets and total weaning weight of litter. In conclusion, the multivariate methods (Cluster Analysis and PCA) has been proven to be a very effective method to obtain a synthetic judgment of reproductive traits in pig.

Key words: the reproductive traits, Cluster Analysis, Principal Component Analysis, interbreeding combinations, pig.

\section{Порівняльний аналіз відтворювальних ознак та кластерний аналіз свиней різних порід}

\author{
С.С. Крамаренко, С.І. Луговий, А.В. Лихач, О.С. Крамаренко, В.Я. Лихач \\ Миколаївський національний аграрний університет, м. Миколаӥв, Украӥна
}

Дані було отримано від 149 голів семи генетичних груп свиней, які утримувалися в ТОВ «Таврійські свині» (Херсонська область, Україна). До аналізу було включено наступні генетичні групи: $L W \times L W(n=19), L W \times L N(n=43), L W \times P T(n=13), L N \times$ $L N(n=15), U M \times L N(n=23), U M \times P T(n=17)$ та $U M \times U M(n=16)$. Метою даної роботи була оцінка відтворювальних ознак тварин з використанням методів багатовимірного аналізу. Для кожної свиноматки було оиінено наступні ознаки: загальна кількість поросят при народженні (TNB), багатоплідність (NBA), частка мертвонароджених поросят (FSB), загальна маса гнізда при народженні (TLBW), великоплідність (APBW), смертність поросят до відлучення (PWM), кількість поросят при відлученні (NW), загальна маса гнізда при відлученні (TWWL) та середня маса одного поросяти при відлученні (APWW). Після стандартизації вихід- 
них даних їх було проаналізовано за допомогою багатовимірних методів (Кластерний Аналіз та Аналіз Головних Компонент) з використанням програми STATISTICA (StatSoft Ltd.) для того, щоб визначити групи міжпородних поєднань на підставі ступеня їх подібності та перевірити дискримінаційну здатність ознак відтворення свиней у формуванні ичих груп. Отримана дендрограма демонструє наявність суттєвих відмінностей між вивченими генетичними групами. Застосування Кластерного Аналізу дозволяє виділити два різні кластери, один з яких містить поєднання UM $\times$ LN та UM $\times U M$, а інший - решту генетичних груп свиней, ияо аналізувалися. Власні значення для перших двох Головних Компонент (РС1 та РС2) в сумі складають близько 65\% варіації вихідної матриці відтворювальних ознак свиней. Перша Головна Компонента (РС1) пояснює 34,9\% загальної мінливості. Вона характеризується суттєвими позитивними навантаженнями для TNB, NBA та TLBW. Друга Головна Компонента (РС2) описує додаткові 29,7\% узагальненої дисперсї і представлена значними навантаженнями для NW, TWWL та АPWW. Таким чином, РC1 може бути інтерпретована, як «багатоплідність та маса гнізда при народженні», а РС2 - як «кількість поросят та маса гнізда на момент відлучення». В иілому, багатовимірні методи (Кластерний Аналіз та АГК) є дуже ефективним методом для проведення комплексного аналізу відтворювальних ознак свиней.

\section{Ключові слова: відтворювальні ознаки, Кластерний Аналіз, Аналіз Головних Компонент, міжпородні поєднання, свині.}

\section{Вступ}

Виробництво свинини на гібридній основі можливе тільки при наявності високопродуктивних материнських і батьківських форм, вивчених на поєднаність. На продуктивність свиней при чистопородному розведенні і схрещуванні впливають різноманітні фактори та умови, зокрема комбінаційна здатність, що відіграє основну роль у проявленні гетерозисного ефекту. Тому пошук оптимальних варіантів поєднань генотипів є одним із пріоритетних у сучасних умовах, оскільки це дасть змогу значно підвищити продуктивність, а, отже, і рентабельність галузі (Vovk, 2011; Berezovskyi et al., 2012; Leonidov et al., 2016; Lazarevich et al., 2016).

При цьому, відтворювальні якості свиней оцінюються більше, ніж за 20-ма показниками, між якими існує значна інтеркореляція, що потребує використання багатовимірних методів аналізу (Fahmy and Bernard, 1972; Biensen et al., 1999).

Таким чином, головною метою нашої роботи став порівняльний аналіз відтворювальних ознак свиней за різних породних поєднань із використанням комплексного підходу, що базується на запровадженні алгоритмів багатовимірного аналізу, а саме, Кластерного та Аналізу Головних Компонент.

\section{Матеріал і методи досліджень}

В аналізі було використано дані щодо 149 свиноматок, що утримувалися в умовах ТОВ «Таврійські свині» Скадовського району Херсонської області протягом 2017 року.

Свиноматки належали до трьох порід - великої білої (LW), ландрас (LN) та української м'ясної (UM). Їх було спаровано із кнурами чотирьох різних порід великої білої (LW), ландрас (LN), п’єтрен (РT) та української м'ясної (UM). Відповідно, до аналізу було включено сім міжпородних поєднань: LW $\times$ LW $(n=$ $19), \mathrm{LW} \times \mathrm{LN}(n=43), \mathrm{LW} \times \mathrm{PT}(n=13), \mathrm{LN} \times \mathrm{LN}(n=$ $15), \mathrm{UM} \times \mathrm{LN}(n=23), \mathrm{UM} \times \mathrm{PT}(n=17)$ та $\mathrm{UM} \times \mathrm{UM}$ $(n=16)$. Для кожної свиноматки було оцінено наступні ознаки відтворення: загальна кількість поросят при народженні (TNB - total no. piglets born), багатоплідність (NBA - no. piglets born alive), частка мертвонароджених поросят (FSB - freq. of stillborn piglets), загальна маса гнізда при народженні (TLBW - total litter birth weight), середня маса одного поросяти при народженні, тобто, великоплідність (АРВW - average piglet birth weight), смертність поросят до відлучення (PWM - pre-weaning mortality in piglets), кількість поросят при відлученні (NW - no. weaned piglets), загальна маса гнізда при відлученні (TWWL - total weaning weight of litter) та середня маса одного поросяти при відлученні (APWW - average piglet weaning weight).

Всі вихідні дані були попередньо стандартизовані:

$$
z_{i}=\frac{X_{i}-\bar{X}}{\sigma},
$$

де $X_{i}$ - значення певної ознаки $i$-тої тварини; $\bar{X}-$ загальне середнє арифметичне значення; $\sigma$ - загальне середнє квадратичне відхилення. Після цього всі ознаки мали середнє арифметичне, що дорівнює 0 , та варіансу, що дорівнює 1.

Кластеризацію груп було проведено на підставі матриці середніх стандартизованих оцінок для всіх дев'яти ознак одночасно, що дало змогу нівелювати вплив різних масштабів та одиниць виміру, з використанням метрики «евклідова відстань» та методу Уорда (Ward's method).

Всі розрахунки було проведено за допомогою пакету прикладних програм STATISTICA v. 6 (Halafyan, 2007).

\section{Результати та їх обговорення}

Відмічаються значні коливання середніх арифметичних оцінок відтворювальних ознак, що аналізувалися, у тварин різних міжпородних поєднань (табл. 1).

Але найбільшою проблемою порівняльного аналізу є те, що неможливо визначити однозначно найкращу групу тварин, тобто, таке міжпородне поєднання, що мало б перевагу над іншими за всіма (чи більшістю найсуттєвіших) відтворювальними ознаками. Так, наприклад, свині групи LW × LW характеризуються найвищими показниками загальної кількості поросят при народженні (11,8 гол.) та великоплідності (1,9 кг). Водночас, свині групи LN $\times$ LN мали найвищу загальну масу гнізда при народженні (18,0 кг) та при відлученні (189,2 кг).

Таким чином, дана проблема потребує іншого вирішення, ніж просте порівняння груп тварин одна 3 одною за кожною ознакою, що включено до аналізу, а саме - комплексного підходу, що одночасно враховував би міру відмінностей між кожною парою міжпородних поєднань за всіма ознаками одночасно. 
Таблиця 1

Показники мінливості відтворювальних ознак свиней за різних міжпородних поєднань, $\bar{X} \pm S_{\bar{X}}$

\begin{tabular}{|c|c|c|c|c|c|c|c|}
\hline \multirow[t]{2}{*}{ Ознака } & \multicolumn{7}{|c|}{ Міжпородні поєднання } \\
\hline & $\mathrm{LW} \times \mathrm{LW}$ & $\mathrm{LW} \times \mathrm{LN}$ & $\mathrm{LW} \times \mathrm{PT}$ & $\mathrm{LN} \times \mathrm{LN}$ & $\mathrm{UM} \times \mathrm{LN}$ & $\mathrm{UM} \times \mathrm{PT}$ & $\overline{\mathrm{UM} \times \mathrm{UM}}$ \\
\hline TNB & $11,8 \pm 0,8$ & $11,5 \pm 0,6$ & $11,6 \pm 0,6$ & $11,1 \pm 0,9$ & $10,3 \pm 0,6$ & $10,8 \pm 0,7$ & $10,5 \pm 0,6$ \\
\hline NBA & $10,5 \pm 0,9$ & $10,8 \pm 0,5$ & $11,2 \pm 0,5$ & $10,7 \pm 0,9$ & $9,8 \pm 0,6$ & $10,4 \pm 0,6$ & $10,1 \pm 0,6$ \\
\hline FSB $(\%)$ & $9,3 \pm 4,7$ & $5,6 \pm 1,4$ & $3,9 \pm 1,5$ & $3,6 \pm 1,5$ & $4,9 \pm 1,5$ & $3,6 \pm 1,3$ & $4,2 \pm 1,5$ \\
\hline TLBW (кг) & $16,7 \pm 0,8$ & $17,3 \pm 0,6$ & $17,2 \pm 0,8$ & $18,0 \pm 0,9$ & $16,6 \pm 0,7$ & $17,5 \pm 0,8$ & $16,0 \pm 0,7$ \\
\hline APBW (кг) & $1,9 \pm 0,3$ & $1,6 \pm 0,1$ & $1,6 \pm 0,1$ & $1,8 \pm 0,1$ & $1,7 \pm 0,1$ & $1,7 \pm 0,1$ & $1,6 \pm 0,1$ \\
\hline PWM (\%) & $11,6 \pm 3,7$ & $12,1 \pm 2,5$ & $9,6 \pm 2,6$ & $17,4 \pm 5,3$ & $19,4 \pm 4,5$ & $12,6 \pm 3,9$ & $17,6 \pm 4,7$ \\
\hline NW & $10,3 \pm 0,3$ & $10,1 \pm 0,3$ & $10,6 \pm 0,4$ & $10,4 \pm 0,5$ & $8,8 \pm 0,5$ & $9,9 \pm 0,2$ & $8,7 \pm 0,4$ \\
\hline TWWL (кг) & $164,9 \pm 6,7$ & $180,3 \pm 6,3$ & $179,2 \pm 6,9$ & $189,2 \pm 7,8$ & $173,5 \pm 9,2$ & $173,5 \pm 8,6$ & $153,9 \pm 9,2$ \\
\hline APWW (кг) & $16,7 \pm 0,6$ & $16,9 \pm 0,7$ & $15,9 \pm 1,5$ & $18,1 \pm 0,6$ & $19,1 \pm 0,6$ & $17,3 \pm 0,6$ & $16,9 \pm 0,7$ \\
\hline
\end{tabular}

Примітка. Тут і далі: TNB - загальна кількість поросят при народженні; NBA - багатоплідність; FSB - частка мертвонароджених поросят; TLBW - загальна маса гнізда при народженні; APBW - середня маса одного поросяти при народженні, тобто, великоплідність; PWM - смертність поросят до відлучення; NW - кількість поросят при відлученні; TWWL - загальна маса гнізда при відлученні; APWW - середня маса одного поросяти при відлученні.

Можливим рішенням даної проблеми могло би стати використання багатовимірної процедури Кластерного Аналізу.

Алгоритм Кластерного Аналізу раніше вже було використано в дослідженнях 3 генетики та селекції сільськогосподарських тварин. Так, було показано, що Кластерний Аналіз на підставі одержаних показників генетичної подібності між різними групами тварин дозволяє детально охарактеризувати генетичну структуру стада, що суттєво полегшує планування необхідних селекційних заходів 3 підвищення ефективності племінної роботи (Herasymenko, 2008). Застосування Кластерного Аналізу при вивченні вікової динаміки несучості у індиків дало змогу визначити наявність чітко виражених етапів яєчної продуктивності: нарощування, «плато» та зниження несучості (Katerynych, 2012). Використовувався Кластерний Аналіз і для визначення співвідносної мінливості та класифікації порід на підставі різних груп ознак (продуктивних або морфологічних) великої рогатої худоби (McManus et al., 2011), свиней (Delgado et al., 2000), кіз (Arandas et al., 2017), віслюків (Gupta et al., 2017), птиці (Grużewska et al., 2009) та ін.

Застосування Кластерного Аналізу до результатів порівняльного аналізу відтворювальних ознак свиней за різних міжпородних поєднань дає можливість виділити дві групи тварин, що характеризуються різним проявом відтворювальних якостей (рис. 1).

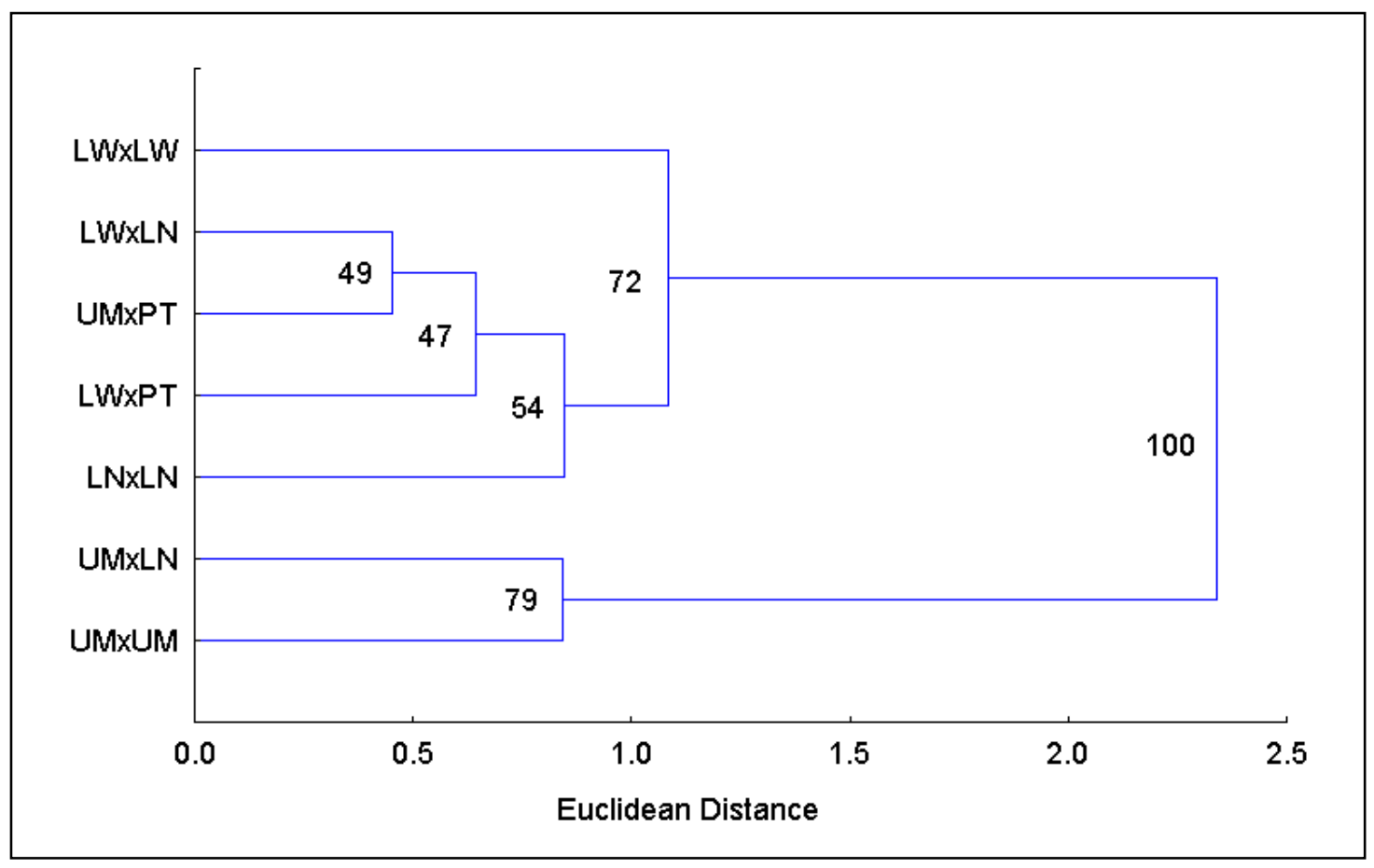

Рис. 1. Дендрограма подібності різних міжпородних поєднань свиней за відтворними ознаками. (Наведено бутстреп-оцінки вірогідності формування відповідних «гілок») 
В перший кластер увійшли тварини груп $\mathrm{UM} \times \mathrm{LN}$ та $\mathrm{UM} \times \mathrm{UM}$, тоді як решта міжпородних поєднань формують інший кластер. Причому, формування цих двох кластерів було підтверджено з використанням бутстреп-оцінки із 100\% вірогідністю.

3 іншого боку, отримана дендрограма подібності не дає можливості однозначно визначити, які ж із використаних ознак мають найбільшу «вагу» при дискримінації об'єктів. Враховуючи, що більшість 3 них суттєво корелюють між собою, найбільш адекватним підходом до їх аналізу є використання Аналізу Головних Компонент (РСА). Особливості використання та переваги даного методу нами вже було проілюстровано раніше (Kramarenko et al., 2017).

У цілому, перші дві Головні Компоненти описують близько 65\% загальної мінливості (ко)варіаційної матриці відтворювальних ознак свиней (табл. 2).

\section{Таблиця 2}

Факторні навантаження для перших двох Головних Компонент, розрахованих на підставі (ко)варіаційної матриці відтворних ознак свиней різних міжпородних поєднань

\begin{tabular}{ccc}
\hline \multirow{2}{*}{ Ознака } & \multicolumn{2}{c}{ Головна Компонента } \\
\cline { 2 - 3 } & РC1 & PC2 \\
\hline TNB & $\mathbf{0 , 9 4 3}$ & $-0,142$ \\
NBA & $\mathbf{0 , 9 8 8}$ & 0,037 \\
FSB & $-0,088$ & $-0,415$ \\
NW & 0,414 & $\mathbf{0 , 6 0 3}$ \\
PWM & $-0,584$ & 0,501 \\
TLBW & $\mathbf{0 , 7 3 7}$ & 0,461 \\
TWWL & 0,145 & $\mathbf{0 , 9 2 5}$ \\
APBW & $-0,355$ & 0,566 \\
APWW & $-0,245$ & $\mathbf{0 , 6 8 8}$ \\
\hline Частка мінливості, \% & 34,9 & 29,7 \\
\hline
\end{tabular}

Примітка. Позначення ознак як у табл. 1. Напівжирним шрифтом виділено ознаки, що вносять найбільший вклад в інтерпретацію відповідних Головних Компонент.

Перша Головна Компонента (PC1) пояснює 34,9\% мінливості та характеризується дуже високими та позитивними навантаженнями на ознаки, що відображають кількісні та якісні оцінки поросят (та гнізда в цілому) при народженні (TNB, NBA та TLBW). Таким чином, PC1 може бути інтерпретована, як «багатоплідність та маса гнізда при народженні».

Друга Головна Компонента (РС2) описує 29,7\% загальної мінливості та, навпаки, більшою мірою пов'язана із ознаками, що характеризують як окремо поросят, так і гніздо в цілому на момент відлучення (NW, TWWL та APWW). Таким чином, вона може бути інтерпретована як «кількість поросят та маса гнізда на момент відлучення».

Оскільки Головні Компоненти ортогональні одна до одної, можна припустити, що формування відтворних ознак свиней залежать від ряду факторів, що ді- ють незалежно та мають прояв на різних етапах як внутрішньоутробного, так і постнатального розвитку.

Раніше, Аналіз Головних Компонент (АГК) вже використовувався при вивченні процесів формування продуктивних та морфологічних ознак свиней. Так, у роботі A. Karlsson (1992) за допомогою АГК було проведено аналіз взаємозв'язків між ознаками якості м'яса свиней, що дозволило автору швидко та однозначно проводити оцінку класності зразків та прискорити селекційну роботу. В подальшому даний підхід було використано в роботах О. Franci et al. (2001), Y. Hu et al. (2006) та R. Ros-Freixedes et al. (2014). Також АГК активно використовувався при дослідженні лінійних промірів тіла (Van Steenbergen, 1989), краніометричних ознак (Gregory and Whelehan, 1983), ростових процесів на різних етапах відгодівлі (Okoro et al., 2015), етологічних характеристик свиней (Czycholl et al., 2017) та ін. Також є приклади вдалого використання АГК при дослідженні особливостей мінливості відтворювальних ознак свиноматок (Young et al., 1977; 1978).

Однією з переваг АГК є можливість провести ординацію об'єктів в просторі перших двох (чи трьох) Голових Компонент із відомими факторними навантаженнями. Це дає змогу як визначити взаємне розташування об'єктів (чи їх груп) по відношенню один до одного, так і ідентифікувати ознаки (чи латентні фактори), що найбільшою мірою сприяють їх дискримінації (Shebanin et al., 2008).

На рис. 2 наведено ординацію центроїдів різних міжпородних поєднань свиней у просторі перших двох Головних Компонент, розрахованих на підставі (ко)варіаційної матриці відтворювальних ознак (див. табл. 2).

Як бачимо, міжпородні поєднання, що аналізувалися, формують три групи. Перша група (поєднання $\mathrm{UM} \times \mathrm{UM}$ та $\mathrm{UM} \times \mathrm{LN}$ ) характеризується низькими навантаженнями за РC1 та РС2, що свідчить про низький прояв відтворювальних ознак. Тварини групи $\mathrm{LN} \times \mathrm{LN}$, навпаки, характеризуються високими оцінками кількості поросят та маси гнізда як при народженні, так і при відлученні. Решта міжпородних поєднань мають прояв ознак близький до середнього.

Характерно, що в ряді сполучень $\mathrm{UM} \times \mathrm{UM}$, $\mathrm{UM} \times \mathrm{LN}$ та LN $\times$ LN, свиноматки української м'ясної породи, які були спаровані із кнурами породи ландрас, характеризувалися оцінками відтворювальних ознак, близькими до поєднання UM × UM, що може свідчити про більш суттєвий вплив материнської породи, ніж породи кнура-плідника.

3 іншого боку, свиноматки, що були спаровані із кнурами породи п'єтрен (поєднання UM × РT та LW $\times$ PT) класифікувалися разом (рис. 1,2$)$, що може свідчити в даному випадку про більш суттєвий вплив породи кнура-плідника на прояв відтворювальних ознак свиноматок. 


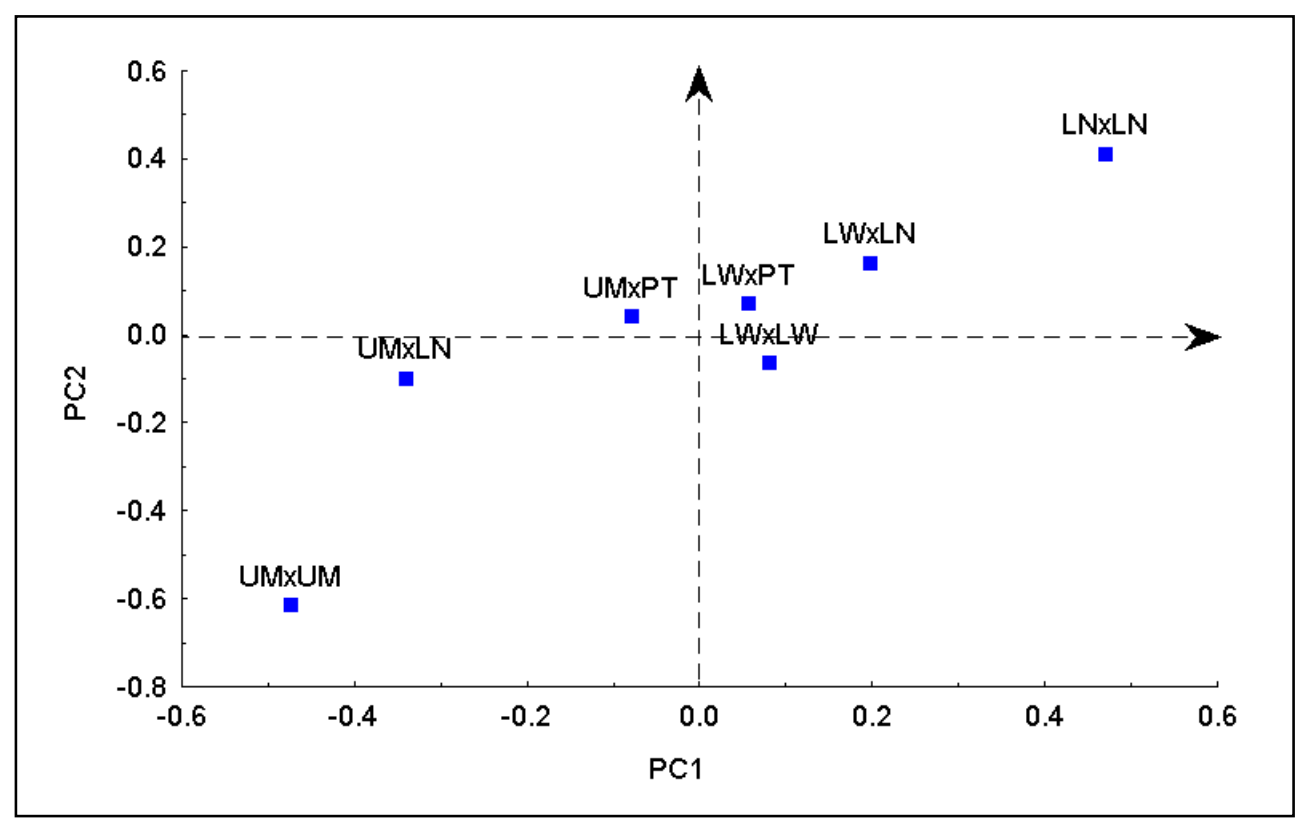

Рис. 2. Центроїди різних міжпородних поєднань свиней у просторі перших двох Головних Компонент, розрахованих на підставі (ко)варіаційної матриці відтворювальних ознак

\section{Висновки}

1. Застосування Кластерного Аналізу дозволило виділити дві різні групи (кластери), один з яких містив міжпородні поєднання UM $\times$ LN та UM $\times$ UM, a інший - решту генетичних груп свиней, що аналізувалися.

2. Перша Головна Компонента (РС1) пояснює 34,9\% загальної мінливості та характеризується суттєвими позитивними навантаженнями для TNB, NBA та TLBW. Друга Головна Компонента (РC2) описує додаткові 29,7\% узагальненої дисперсії і представлена значними навантаженнями для NW, TWWL та APWW. Таким чином, PC1 може бути інтерпретована, як «багатоплідність та маса гнізда при народженні», а РС2 - як «кількість поросят та маса гнізда на момент відлучення».

3. Оскільки Головні Компоненти ортогональні одна до одної, можна припустити, що формування відтворювальних ознак свиней залежать від ряду факторів, що діють незалежно та мають прояв на різних етапах як внутрішньоутробного, так і постнатального розвитку.

4. В цілому, багатовимірні методи (Кластерний Аналіз та АГК) є дуже ефективним методом для проведення комплексного аналізу відтворювальних ознак свиней.

Подяки. Робота виконана в рамках держбюджетної тематики Міністерства освіти і науки України (номер державної реєстрації 0117U000485).

\section{References}

Arandas, J.K.G., da Silva, N.M.V., Nascimento, R.B., Filho, E.C.P., de Albuquerque Brasil, L.H., \& Ribeiro, M.N. (2017). Multivariate analysis as a tool for phe- notypic characterization of an endangered breed. Journal of Applied Animal Research. 45(1), 152-158. doi: 10.1080/09712119.2015.112535

Berezovskyi, M.D., Popova, V.M., Tsyryk, K.O., \& Ohurenko, V.S. (2012). Vidtvoriuvalni yakosti svynomatok v systemi hibrydyzatsii. Svynarstvo. 60, 21-24 (in Ukrainian).

Biensen, N.J., Haussmann, M.F., Lay, D.C., Christian, L.L., \& Ford, S.P. (1999). The relationship between placental and piglet birth weights and growth traits. Animal Scienc. 68(4), 709-715. doi: 10.1017/S1357729800050736

Delgado, J.V., Barba, C., Rodero, A., Dieguez, E., Canuelo, P., \& Herrera, M. (2000). Morphological characterization of the Iberian pig branch based on quantitative traits. In: Almeida J.A. \& Tirapicos Nunes J. (eds.). Tradition and innovation in Mediterranean pig production. Zaragoza: CIHEAM, 63-66.

Fahmy, M.H., \& Bernard, C.S. (1972). Interrelations between some reproductive traits in swine. Canadian Journal of Animal Science. 52(1), 39-45. doi: $10.4141 /$ cjas72-004

Franci, O., Pugliese, C., Bozzi, R., Acciaioli, A., \& Parisi, G. (2001). The use of multivariate analysis for evaluating relationships among fat depots in heavy pigs of different genotypes. Meat Science. 58(3), 259-266. doi: 10.1016/S0309-1740(00)00163-7

Halafyan, A.A. (2007). STATISTICA 6. Statisticheskij analiz dannyh. M.: OOO «Binom-Press» (in Russian).

Herasymenko, V.V. (2008). Do pytannia pro vykorystannia indeksiv henetychnoi skhozhosti v selektsii silskohospodarskykh tvaryn. Naukovyi visnyk «AskaniiaNova». 1, 107-113 (in Ukrainian).

Gregory, N.G., \& Whelehan, O.P. (1983). Skull shape in relation to carcass fatness in pigs. Journal of the Sci- 
ence of Food and Agriculture. 34(12), 1397-1403. doi: $10.1002 /$ jsfa. 2740341213

Gruzewska, A., Biesiada-Drzazga, B., \& Markowska, M. (2009). Application of multidimensional comparative analysis in comparing commercial broiler chicken lines. Archiv fur Geflugelkunde. 73(2), 132-138.

Czycholl, I., Beilage, E.G., Henning, C., \& Krieter, J. (2017). Reliability of the qualitative behavior assessment as included in the Welfare Quality Assessment protocol for growing pigs. Journal of Animal Science. 95(8), 3445-3454. doi: 10.2527/jas.2017.1525

Gupta, A.K., Kumar, S., Pal, Y., Brahmane, M., Kumar, B., et al. (2017). Phenotypic Clustering of Indian Donkey Population Belonging to Six Agro-Climatic Regions. Journal of Biodiversity \& Endangered Species. 5, 201. doi: 10.4172/2332-2543.1000201

Hu, Y., Suzuki, T., Noguchi, G., Li, Y., Kitamura, Y., \& Satake, T. (2006). Study on evaluation of carcass traits and pork quality using principal component analysis. Nogyo Shisetsu (Journal of the Society of Agricultural Structures, Japan). 37(4), 173-182. doi: $10.11449 /$ sasj1971.37.173

Karlsson, A. (1992). The use of principal component analysis (PCA) for evaluating results from pig meat quality measurements. Meat science. 31(4), 423-433. doi: 10.1016/0309-1740(92)90025-Y

Katerynych, O. (2012). Minlyvist «nesuchosti» v ontohenezi u indykiv krosu «Kharkivskyi». Tvarynnytstvo Ukrainy. 4, 23-26 (in Ukrainian).

Kramarenko, S., Kuzmicheva, N., \& Kramarenko, A. (2017). Principal component analysis of the exterior traits in dairy cows. Scientific Messenger of LNU of Veterinary Medicine and Biotechnologies. 19(79), 4852. doi: 10.15421/nvlvet7910

Lazarevich, A.N., Efimova, L.V., \& Ivanova, O.V. (2016). Analysis of the effectiveness crossing of hybrid sows with thoroughbred and terminal sires. In the World of Scientific Discoveries. 12(84), 108-129. doi: 10.12731/wsd-2016-12-108-129

Leonidov, I.N., Kozlikin, A.V. \& Lodianov, V.V. (2016). Reproductive, fattening and meat qualities of young pigs at using boars of specialized breeds and types. Polythematic online scientific journal of Kuban State
Agrarian University. 122(8), 1-10. doi: 10.21515/1990-4665-122-008

McManus, C., Castanheira, M., Paiva, S.R., Louvandini, H., Fioravanti, M.C.S., Paludo, G.R., et al. (2011). Use of multivariate analyses for determining heat tolerance in Brazilian cattle. Tropical animal health and production. 43(3), 623-630. doi: 10.1007/s11250-0109742-8

Okoro, V.M., Ogundu, U.E., Okani, M., Oziri, I., Eneowo, O., Olisenekwu, O.T., et al. (2015). Principal Component Analysis of Conformation and Blood Marker Traits at Pre-and Post-Weaning Stages of Growth in F2 Crossbred Nigerian Indigenous $\times$ Landrace Pigs. Animal biotechnology. 26(4), 243-250. doi: 10.1080/10495398.2015.1014043

Ros-Freixedes, R., Sadler, L.J., Onteru, S.K., Smith, R.M., Young, J.M., Johnson, A.K., et al. (2014). Relationship between gilt behavior and meat quality using principal component analysis. Meat science. 96(1), 264-269. doi: 10.1016/j.meatsci.2013.07.004

Shebanin, V.S., Melnyk, S.I., Kramarenko, S.S. \& Ganganov, V.M. (2008). Analiz struktury populiatsii. Mykolaiv: MDAU (in Ukrainian).

Van Steenbergen, E.J. (1989). Description and evaluation of a linear scoring system for exterior traits in pigs. Livestock Production Science. 23(1-2), 163-181. doi: 10.1016/0301-6226(89)90012-2

Vovk, V.O. (2011). Reproduktyvni yakosti svynomatok riznykh henotypiv pry chystoporodnomu rozvedenni ta skhreshchuvanni. Svynarstvo. 59, 32-35 (in Ukrainian).

Young, L.D., Johnson, R.K., \& Omtvedt, I.T. (1977). An Analysis of the Dependency Structure between a Gilt's Prebreeding and Reproductive Traits. II. Principal Component Analysis 1. Journal of Animal Science. 44(4), 565-570. doi: 10.2527/jas1977.444565x

Young, L.D., Pumfrey, R.A., Cunningham, P.J., \& Zimmerman, D.R. (1978). Heritabilities and genetic and phenotypic correlations for prebreeding traits, reproductive traits and principal components. Journal of Animal Science. 46(4), 937-949. doi: $10.2527 /$ jas $1978.464937 \mathrm{x}$ 